TRANSPORT

2008

23(3): $214-220$

\title{
STAKEHOLDER APPROACH IN THE MANAGEMENT OF PUBLIC TRANSPORT COMPANIES
}

\author{
Dalia Susniené ${ }^{1}$, Algirdas Jurkauskas ${ }^{2}$ \\ Kaunas University of Technology, Panevėžys Institute, Klaipédos g. 1, 35209 Panevėžys, Lithuania \\ E-mails: ${ }^{1}$ dalia.susniene@ktu.lt; ${ }^{2}$ algirdas.jurkauskas@ktu.lt
}

Received 29 February; accepted 12 June 2008

\begin{abstract}
The sustainable development of urban mobility cannot be envisaged without a transport system which could be able to meet the needs of citizens and businesses, make a positive impact on the environment and be socially fair and economically efficient. An efficient transport system increases safety, improves network efficiency and stimulates intermodality which reduces transport impact on environment and makes cities more attractive. In order to survive and successfully operate in the market, it is necessary for public transport companies to look for and implement new management models in their system. Every organization is surrounded by the environment and it is very important to examine external factors if an organization wants to gain a strong position in the market which is also important for public transport companies. The involvement of stakeholders in the supply of public transport services i.e. what level of relationships are needed between a transportation company and its various stakeholders is necessary in order to meet the main stakeholder - passenger needs. Consequently, as to supply the passenger with the best service, relationships between different stakeholders (municipality, public transport company, state road maintenance service etc.) are of vital importance. It is essential to emphasise that state institutions and municipalities play a crucial role in managing public transport companies. State institutions influence them through legal instruments and regulations and municipalities, as the main shareholders, through the impact on management board and through subsidizing the company from municipality budget. Therefore, it is very important to have in mind this particularity in managing public transport companies and in the relationships with their stakeholders.
\end{abstract}

Keywords: public transport, stakeholders, needs, services, management model, urban mobility.

\section{Introduction}

Transport forms an essential backbone for socio-economic development but if not developed sustainably it also imposes significant costs on society in terms of environmental and health impacts. Therefore, transport is one of the key sectors in urban development and in many cases it reflects the level of country's socio-economic development (ECTRI... 2007; UITP... 2005; Vinck 2000). The need for communication means is important for both people and companies. Attractive and efficient public transport is an integral part of the modern transport system. The users of transport services actually are all people and businesses. In case of transport disturbances the possibilities of people communication decrease and economic losses are experienced in different activity sectors. If the disturbances of a transport system become persistent (e.g. jams or lack of parking place), it causes difficulties to rationally use resources, reduces labour division, people's economic welfare and the quality of life, and has a negative impact on the environment. Therefore, city planning and management is impossible without an integrated approach (Fig. 1). The integrated approach involves planning processes, especially land use and transport planning.

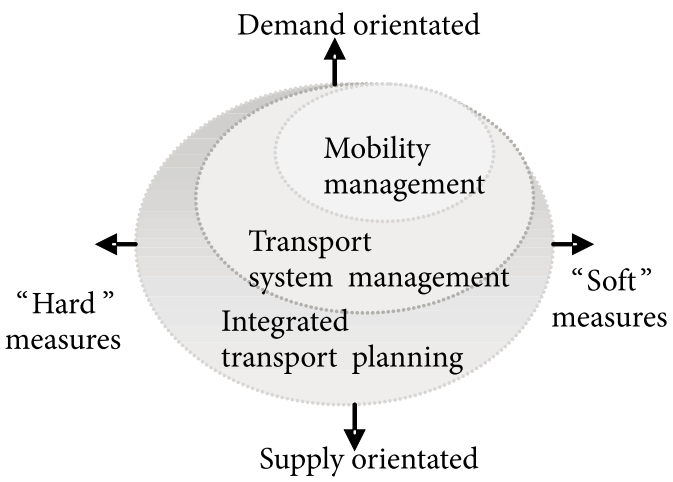

Fig. 1. Levels of Integrated Planning Processes (ECTRI... 2007) 
The object of research: public transport system.

The goal of research: to introduce public transport services from the aspect of stakeholder relationships as a prerequisite for improving the operations of public transport companies.

Research methods: A systemic analysis of academic papers was carried out using a comparative and generalization method. A design of empirical research is framed combining different theories and concepts. Qualitative research methodology was used and the descriptive method was chosen. To conduct the empirical research, sociological research methods - questionnaires and semi-structured interviews - were used. The results were processed using the methods of statistical data analysis and presented in the textual and graphic forms. Mathematical-statistical methods (SPSS Statistical Package for Social Sciences and Microsoft Excel Software Package) allowed ensuring tool's validity and representativity. Descriptive statistics including mean percentages, mode and median, correlation coefficient and regressive analysis was applied.

\section{The role and impact of the public transport system in urban mobility}

The main problems in cities are closely related to the growth of the number of transport means, pollution, lack of parking space etc. Therefore, according to Carnell (2003), the sustainable development of urban mobility cannot be envisaged without a transport system which could be able to meet the needs of citizens and businesses, make a positive impact on the environment and remain socially fair and economically efficient. An efficient transport system increases safety, improves network efficiency and stimulates intermodality which reduces transport impact on environment and makes cities more attractive. A public transport system and its management play a very important role in this field. Even with the constantly increasing number of private cars public transport can play a crucial role as the efficient management of the public transport system is vital to rapid economic growth and people's welfare:

- Good functioning of transport system improves citizens' life (reduces congestions, jams, social segregation and improves environmental quality).

- Generates favourable conditions for reaching work and educational institutions in different places.
- Allows freedom and opportunity to travel for every person and creates highly developed society.

- Efficient transport system can generate added value that cannot be separated from national economic, industrial and service processes.

As public transport is significant to the service sector of common/public interest and offers the possibility of satisfying the demand for movement and supply of the EU people, it becomes significant for highlighting social, economic and territory cohesion claim European Multi Stakeholder Forum (2003) and European Quality Promotion Policy for Improving European Competitiveness (2004). It is emphasised that motivating as many people as possible to use affordable public transport services can contribute to implementing the goals concerning the reduction of greenhouse gas emissions and transport costs as well as emphasizing the value public transport in respect of steady price increase of oil and threat of its decreased refinement in the near future. Currently, the position of private transport in EU is more favourable than that of public transport (Fig. 2).

The car remains the predominant means of passenger travel. The European Commission considers that the growth of cars is an outpacing improvement in the road network and leads to increasing congestion and environmental pollution.

Regarding regional competitiveness and employment the attention primarily is paid to stimulate innovations and knowledge driven economy claims the European Committee for Economic and Social Affairs, especially increasing scientific research and technology development as well as innovation skills in different fields including public transport.

Currently, we experience many changes where public transport can have a great impact. First, urban travelling market constantly increases with the increase of population and its mobility. In this case, public transport can help with avoiding jams and lack of oxygen in the cities. Second (UITP... 2005), people start understanding that public transport can be a key factor in creating healthy, safe, clean, efficient and pleasant cities to live where they will feel comfortably. Third, there are always groups of people that do not have their own means of transport because of old age, disability or low income. According to UITP (2001), giving them a chance to take

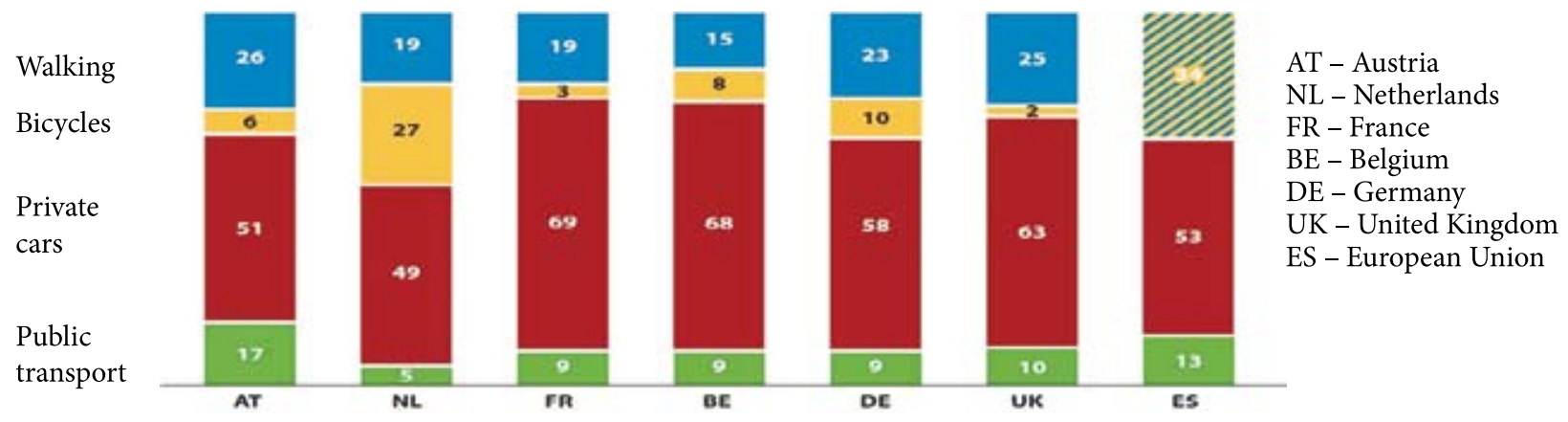

Fig. 2. Modal distribution in European countries in 2006 (source: EUROSTAT) 
part in city life, urban transport is a key factor of social integration.

\section{The need for new management models in public transport services}

In order to survive and successfully operate in the market, it is necessary for public transport companies to look for and implement new management models in their system. Every organization, by Elias (2000) and Ackermann (2001), is surrounded by the environment and it is very important to examine external factors if an organization wants to gain a strong position in the market which is also important for public transport companies. According to Vinck (2000), public transport companies are influenced by different external factors as follows:

- demographic, political, legal, economic, technological and social factors difficult to be influenced;

- specific factors characteristic of the service sector, for instance, privatization, contacting agreements, cooperation among companies, increased significance of leasing and self-service (electronic tickets with multiple functions etc.);

- competitive factors of transport companies;

- factors influenced by customers (passengers) and suppliers.

An external environment analysis is very useful at different levels. According to Eden (1998), Mopin (2000), and HPO... (2006), opportunities and threats are used in strategic planning and is a basis for long-term operation plans in company's departments or are as a starting point for developing strategic plans in different business segments. Analysis of such data could be used for developing potential services as well as for satisfying stakeholder needs at public transport companies.

Stakeholders' involvement in the supply of public transport services i.e. what level of relationships are needed between a transportation company and its various stakeholders is necessary in order to meet the main stakeholder - passenger needs. Consequently, by Gonella (1998), Svendsen (1998), and United Nations SecretaryGeneral (2000), as to supply the passenger with the best service, relationships between different stakeholders (municipality, public transport company, state road maintenance service etc.) are of vital importance. It is essential to emphasise that state institutions and municipalities play a crucial role in managing public transport companies. State institutions influence them through legal instruments and regulations and municipalities, as the main shareholders, through the impact on management board and through subsidizing the company from municipality budget. Therefore, it is very important to have in mind this particularity in managing public transport companies and in the relationships with their stakeholders (Fig. 3).

Service-sector organizations face a higher level of complexity than manufacturing firms requiring management to consider a full range of management practices including:

- best-practice analysis both within an organization and comparisons among similar organizations (peer analysis) to avoid repeating mistakes and to identify management techniques and performance targets;

- process analysis to uncover the ways the service workers interact with customers;

- continual application of quality-management techniques to improve key functions on an ongoing basis.

Transport managers need to consider these issues as critical to the long-term survival of their organizations even if day-to-day management issues could easily absorb most available management attention.

\section{Identification of criteria for meeting stakeholder needs in the management of public transport organizations}

After a thorough analysis of academic literature the criteria and their indicators are identified. They will generate premises for satisfying stakeholder needs at public transport companies and can precondition the validity and reliability of assessing organizational processes and activity in the aspect of stakeholder satisfaction and reveal the strengths and weaknesses of these processes.

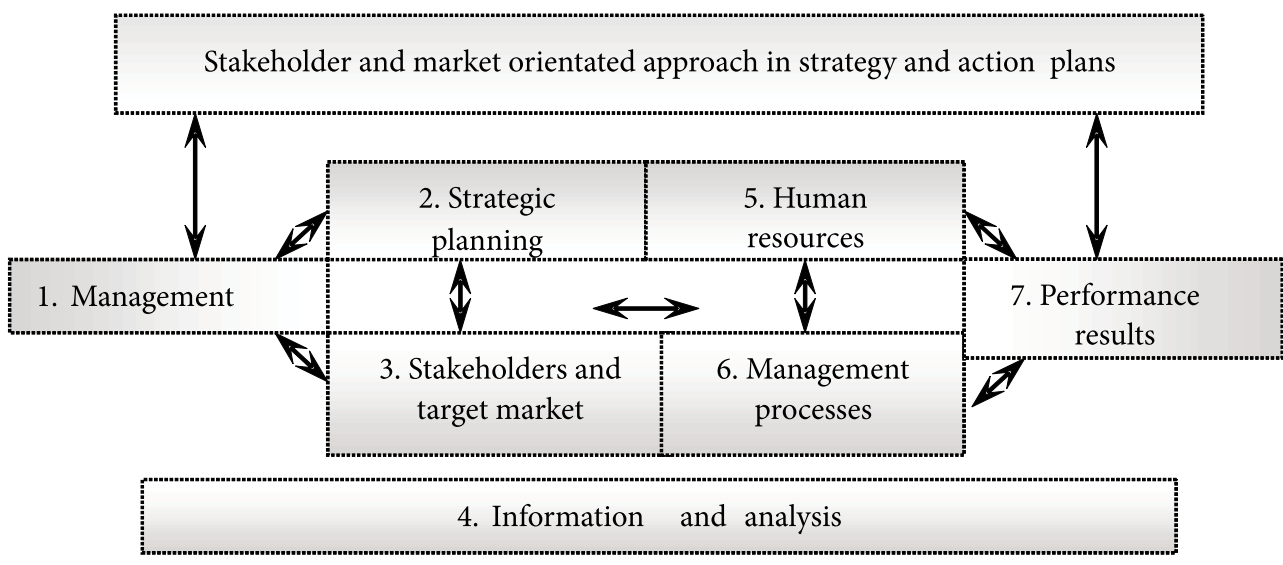

Fig. 3. Structure of service supply (Carnell 2003) 
In accordance with the identified criteria and their indicators a questionnaire was designed and chosen as a research tool at four successfully operating public transport companies. The questionnaire comprises 48 statements (indicators) derived from ten criteria concerning the satisfaction of stakeholder needs:

1. Senior management belief that building relationship with stakeholders is important for bottom-line success ( 9 indicators).

2. Time spent by the managers communicating about building relationship with stakeholders and shared information (4 indicators).

3. Employee readiness to keep relationship with key stakeholders and responsibility (5 indicators).

4. Organization culture support for personal values and needs (8 indicators).

5. Organization orientation to the satisfaction of stakeholder needs (4 indicators).

6. Organization actions ensuring stakeholder satisfaction (7 indicators).

7. Organizational systems set up or redesigned to support the mission (5 indicators).

8. Organization policies geared to long-term success ( 2 indicators).

9. Care for environmental issues (1 indicator).

10. General assessment of stakeholder approach in an organization (3 indicators).

The questionnaire is designed in such a way that a higher point for a statement reflects more efficient satisfaction of stakeholder needs and vice versa a lower point for a statement reflects lower efficiency of organization activity concerning stakeholder satisfaction.

According to the research theory and practice representativity, the reliability and validity of the measuring instrument should be checked. Representativity was revealed by research sample discussing the aggregate. Additionally, for checking reliability, the relationship between criteria from 1 to 9 and criterion 10 was examined because the latter criterion is of general nature and correlates with the first nine ones. Statistically it means that relationship strength is identified between two factors of multidimensional groups. This relationship is analyzed by a canonical correlation method and the strength of the relationship is revealed by the coefficient of canonical correlation $R$ (Table 1 ).

Table 1. Canonical correlation coefficient $R$ comparing criteria $1-9$ and criterion 10

\begin{tabular}{lc}
\hline & Criterion 10 \\
\hline Criterion 1 & 0.58 \\
Criterion 2 & 0.53 \\
Criterion 3 & 0.55 \\
Criterion 4 & 0.61 \\
Criterion 5 & 0.57 \\
Criterion 6 & 0.60 \\
Criterion 7 & 0.58 \\
Criterion 8 & 0.54 \\
Criterion 9 & 0.57 \\
\hline
\end{tabular}

It appeared that criteria from 1 to 9 had a significant correlation with criterion 10 ; i.e. $R$ values are from 0.53 to 0.61 and reliability is $\mathrm{p}<0.0001$. The achieved results show a high level of reliability, and therefore the high reliability of the criteria.

For data analysis the following statistical methods are employed: estimate arithmetic mean, mode, correlation coefficient, regression equation and percentage. Data is analyzed according to the results of every indicator separately taking into account an opinion of employees and senior management. At a later stage, the same procedure is used dealing with categories/dimensions.

\section{Findings of research}

The applied analysis of regression and correlation has revealed that estimating different criteria by employees and senior management correlation coefficient between the score means of these two groups makes 0.42 and shows an average strong relation. The representation of this relation will be found in the form of $y=a x$. The simplified form will allow us to identify how low and different the estimations of employees and senior management are. As shown in Fig. 4, regression equation is $y=1.26 x$ which means that the estimations of senior management are 1.26 times higher than those of employees.

The diagram (Fig. 5) shows the relation of senior management and employees' assessments concerning stakeholder importance to organization.

When estimating the importance of each stakeholder group to organization correlation, the coefficient between score means of employees and senior management answers is 0.484881 and shows an average strong relation.

Comparing all nine dimensions/categories of the questionnaire, the highest percentage from employees got the category "Organization Orientation to the Satisfaction of Stakeholder Needs" (54.4\%). The highest rank from senior management got the categories "Organiza-

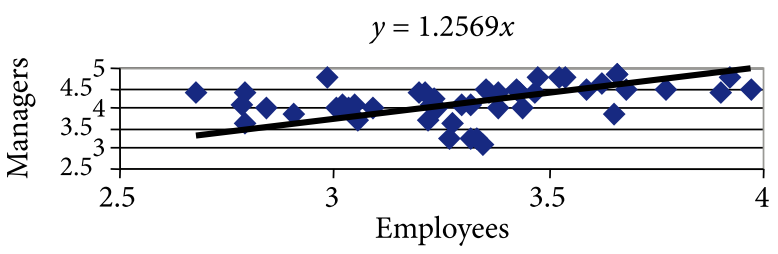

Fig. 4. Comparison of senior management and employees' estimations of the questionnaire statements

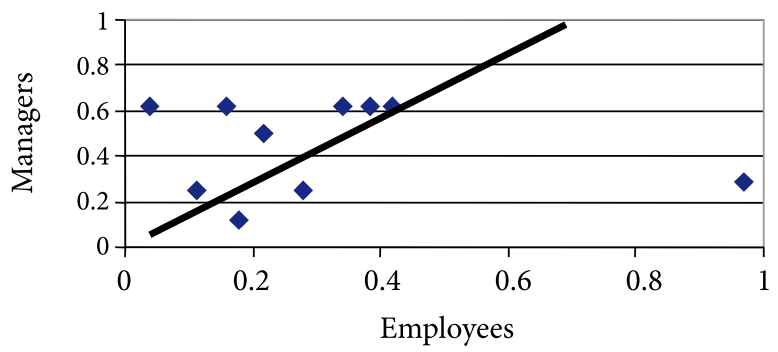

Fig. 5. Stakeholder importance according to senior management and employees' estimations 


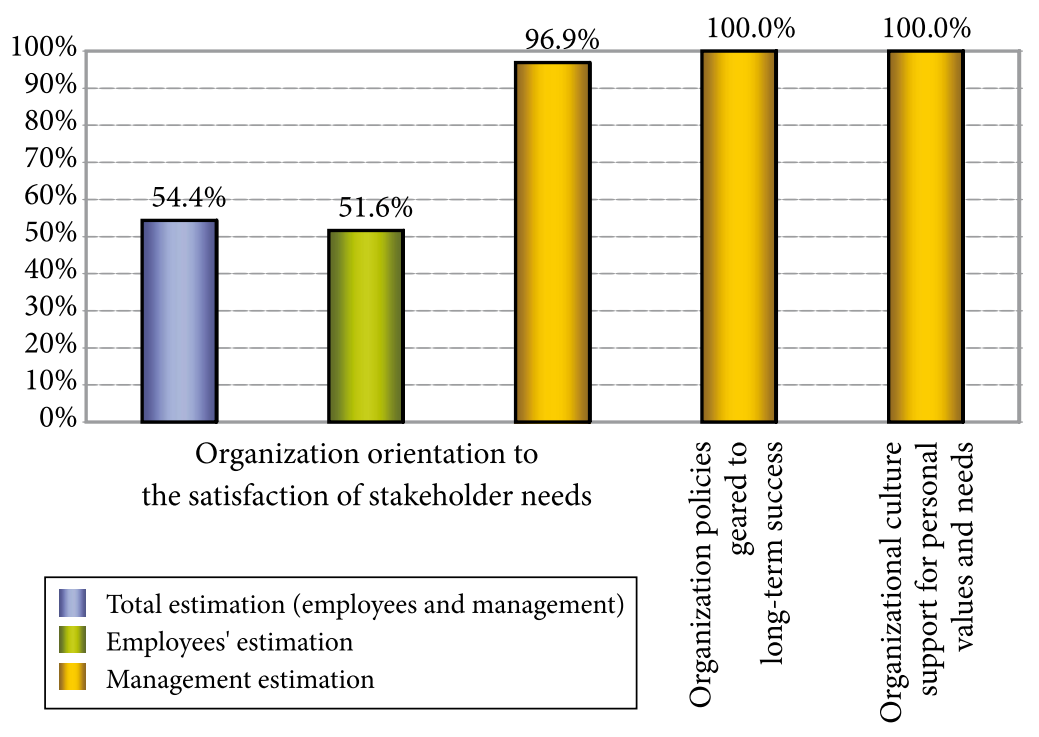

Fig. 6. The highest ranked criteria (total and separately by employees and management)

tion Culture Support for Personal Values and Needs" and "Organization Policies Geared to Long-Term Success" (100\%). However, the highest ranked employee category - "Organization Orientation to the Satisfaction of Stakeholder Needs" - was also evaluated relatively high by the managers (96.9\%) (Fig. 6).

The lowest percentage of the positive answers from the point of view of employees got the categories "Organizational Systems Set Up or Redesigned to Support the Mission" (33.1\%) and "Organization Policies Geared to LongTerm Success" (40.8\%). The biggest part of the respondents gave negative evaluations "no" or "certainly no" (Fig. 7).

It is necessary to say that senior management and employees' opinion on this position was different because from the managers" point of view this position got the highest percentage of the positive answers whereas employees pointed to the lowest percentage of those.

The lowest percentage of the positive answers from the managers got the categories "Employee Readiness to Keep Relationship with Key Stakeholders and Responsibility" (82.5\%) and "Time Spent by Managers Communicating about Building Relationship with Stakeholders and Shared Information" (84.4\%) (Fig. 8).

When analyzing and comparing the indicators (questions, see Fig. 9), the highest evaluation received "Organization Care for its Reputation in Society" $\left(\bar{X}=4.04 ; M_{e}=\right.$ $\left.4 ; M_{o}=5\right)$. Actually, it was the only indicator that got more then four points from the employees. There were more indicators ranked relatively high. For example, "Employees Know the Organization's mission and goals" ( $\bar{X}=3.97 ; M_{e}$ $=4 ; M_{o}=5$ ) and two other indicators "Organization's Aspiration is to Keep Relationships with the Stakeholders" and "Organization's Goal is to Satisfy the Needs of Stakeholders" got the same results ( $\left.\bar{X}=3.91 ; M_{e}=4 ; M_{o}=5\right)$.

The opinion of senior management was different again (Fig. 10). They ranked the other highest indicators "Analysis of the Customers' Complaints" ( $\bar{X}=4.88$; $\left.M_{e}=5 ; M_{o}=5\right)$, "Care for Employee Training", "Permanent Update of Company's Range of Services", "Employee

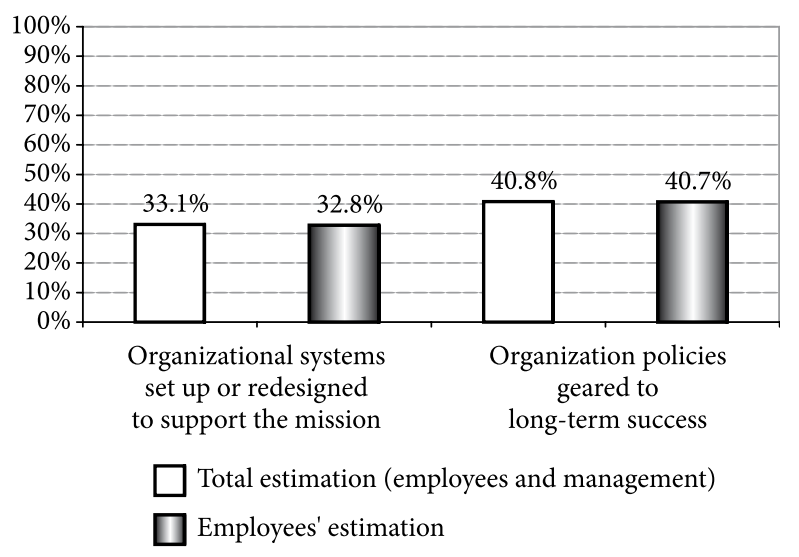

Fig. 7. The lowest ranked criteria

(total and separately by employees and management)

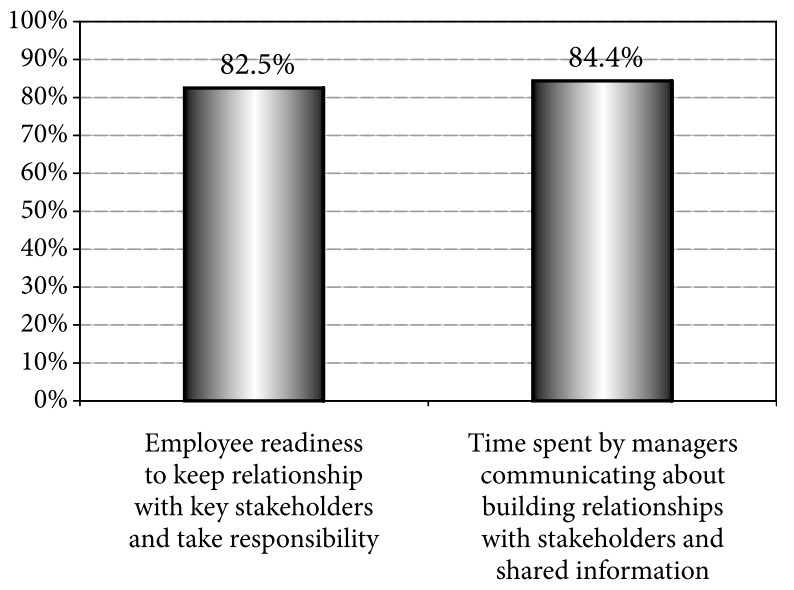

Fig. 8. The lowest ranked criteria by senior management 


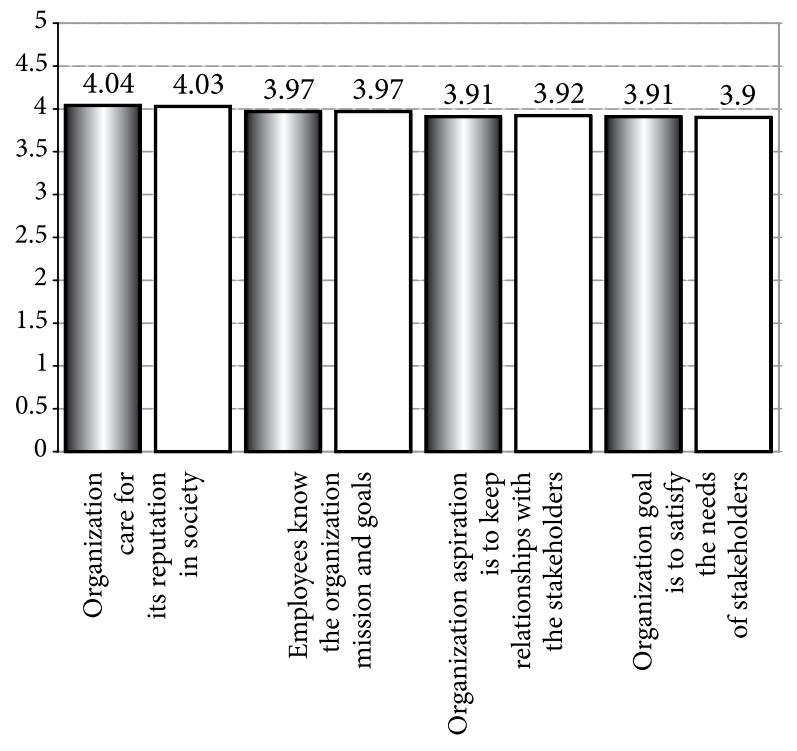

$\square$ Total estimation (employees and management) $\square$ Employees' estimation

Fig. 9. The highest ranked indicators by employees and in total

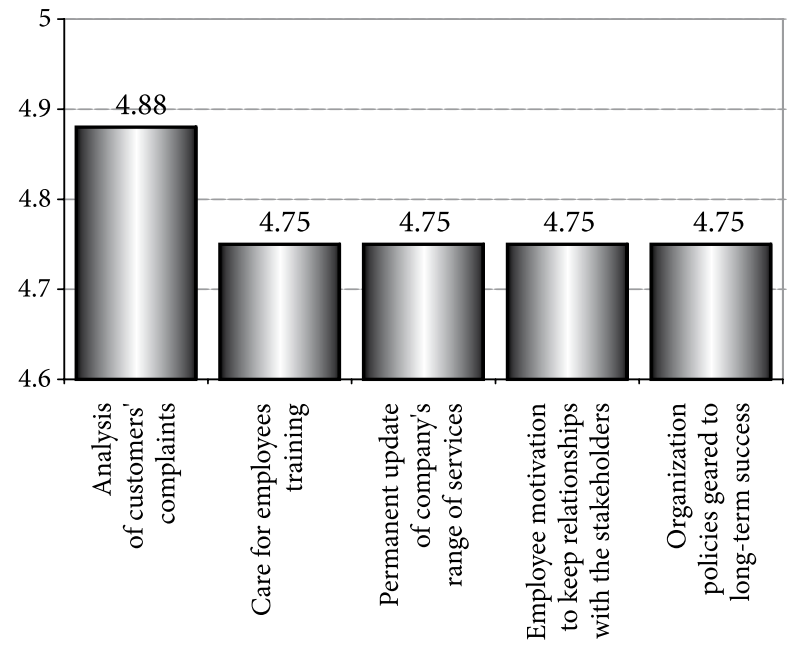

Fig. 10. The highest ranked indicators by senior management

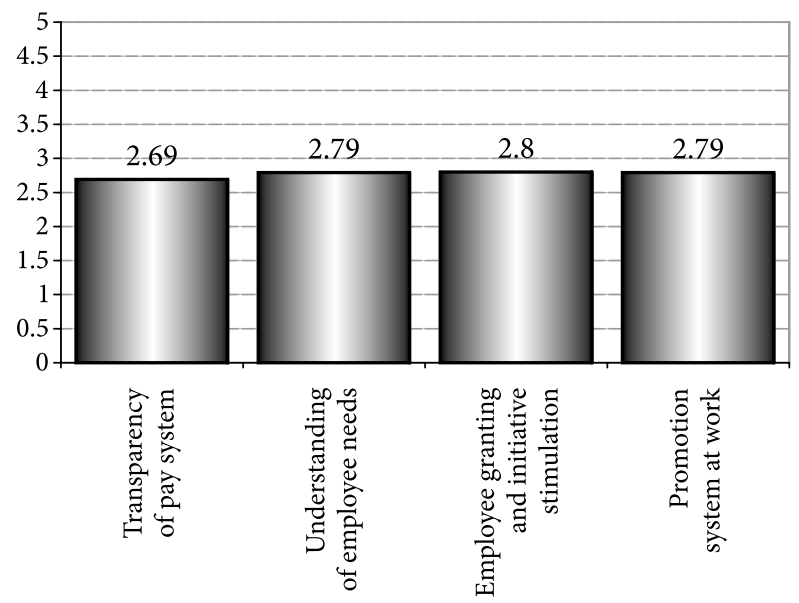

Fig. 11. The lowest ranked indicators by employees
Motivation to Keep Relationships With the Stakeholders" and "Organization's policies geared to long-term success". The indicators were ranked equally high $\left(\bar{X}=4.75 ; M_{e}=\right.$ 5; $\left.M_{o}=5\right)$.

The lowest ranking from employees (Fig. 11) got the indicators "Transparency of Pay System" ( $\bar{X}=2.69$; $M_{e}=2.5 ; M_{o}=1$ ), "Understanding of Employee Needs" ( $\left.\bar{X}=2.79 ; M_{e}=3 ; M_{o}=4\right)$ and "Employee Granting and Initiative Stimulation" ( $\bar{X}=2.79 ; M_{e}=3 ; M_{o}=1$ ). "Promotion System at Work" also received low evaluation ( $\bar{X}$ $=2.80 ; M_{e}=3 ; M_{o}=3$ ).

Senior management (Fig. 12) had a different opinion and ranked the lowest indicator "Manager's Pay Dependency on the Success of the Relationship with the Stakeholders" ( $\left.\bar{X}=3.13 ; M_{e}=4 ; M_{o}=4\right)$. The following indicators "Allocation of Funds for Relationships with the Stakeholders", "Including Cooperation with the Stakeholders into the Functions Regulations" and "Settling Accounts with the Suppliers in Time" were equally ranked $\left(\bar{X}=3.25 ; M_{e}=4 ; M_{o}=4\right)$. As it is apparent from the displayed results, all these indicators got relatively negative evaluations and need attention and corrective actions from the senior management of public transport companies.

When analyzing and taking steps to improve the operations, public transport companies under this research should pay attention to the lowest ranked indicators and categories as well as to find reasons for the present situation and for differences in senior management and employees' opinions.

\section{Conclusions}

Research was carried out at public transport enterprises because the elements of the free market are combined with the elements of the regulatory system there. Therefore, public transport enterprises have specific influential stakeholders and this aspect should be taken into account i.e. appropriate methods should be found to harmonize the interests and needs of different stakeholders and in the bottom-line to assure the satisfaction of stake-

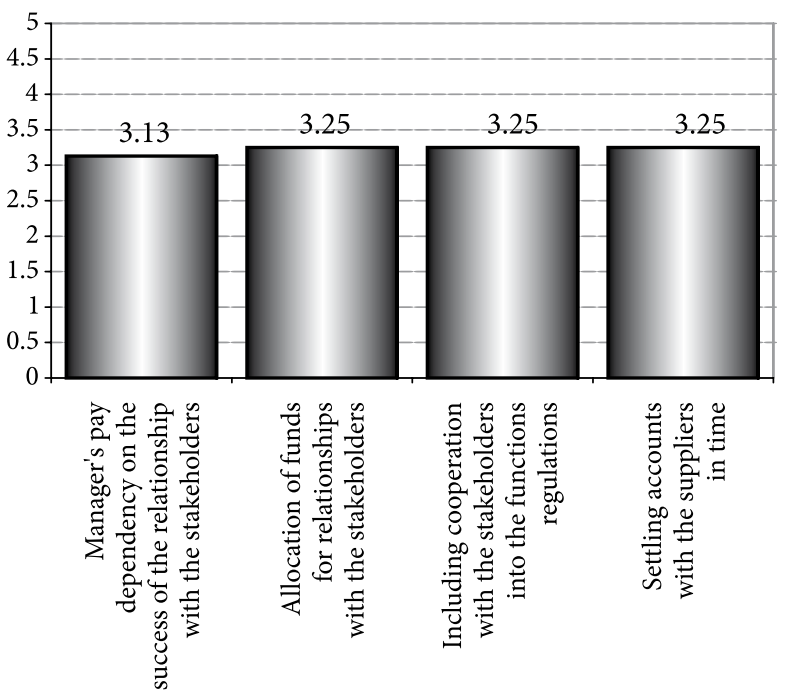

Fig. 12. The lowest ranked indicators by senior management 
holders needs. The research results have revealed that the questionnaire can assure validity, representativity and reliability because relative score mean error is significantly lower than $10 \%$ with $95 \%$ of fiducial probability. This means that the identified criteria and their indicators concerning the satisfaction of stakeholders' needs at public transport (on the basis of which the questionnaire was designed) allows to reliably, objectively and validly assess public transport organization process orientation to the satisfaction of stakeholders' needs.

The carried out empirical research has disclosed that research methodology is suitable and effective for the appraisal of public transport organization performance and management building up relationship with the stakeholders and can assure validity and reliability of the results. It also allows detecting the strengths and weaknesses of public transport organization management when striving to satisfy stakeholders' needs as well as the viewpoint and readiness of employees and senior management to satisfy stakeholders' needs. Consequently, it has been proved that the identified criteria and indicators are reliable and valid in assessing public transport organization orientation to meet stakeholder needs.

\section{References}

Ackermann, F. 2001. Stakeholders matter: techniques for their identification and management. Department of Management Science Research Paper No. 2001/20, Strathclyde Business School, Glasgow.

Carnell, D. S. 2003. Performance excellence system at public transport companies. Available from Internet: <www.atco. org.uk>.

ECTRI's position on the European Commission's Green Paper on Urban Transport, 2007. Available from Internet: <http:// www.ectri.org/Documents/Publications/EC/Green-paperUrban-Transport_ECTRI-Position_\%20April-2007.pdf $>$.

Eden, C. 1998. Making strategy: The journey of strategic management. London: Sage Publications. 117 p.

Elias, A. A. 2000. Stakeholder analysis for systems thinking and modeling. Available from Internet: <www.esc.auckland. ac.nz/organizations/ORSNZ/conf35/paper/BobCavana. pdf $>$.

European multi stakeholder forum on CSR. 2003. Available from Internet: <http://europa.eu.int/comm/enterprise/csr/ forum.htm $>$.

European quality promotion policy for improving European competitiveness. European Commission DG III; Industry, 2004.

Fley, J. K. 2001. From quality management to organization excellence: Don't throw the baby out with the bath water, in Proceedings of the Fourth International and Seventh National Research Conference on Quality Management, Sydney, $\mathrm{p}$. 154-177.

Gonella, C. 1998. Visualising and measuring intellectual performance - the scandia approach. Accountability Quartely 6: 7-20.
HPO. The High Performance Organization Group. 2006. Available from Internet: <http://www.the-hpo.com/ >.

Mopin, P. 2000. Customer defined wuality standards. Presentation to Union of public transport international conference. Available from Internet: <www.publ./lit45_html>.

Svendsen, A. 1998. The stakeholder strategy: profiting from collaborative business relationships. Berret-Koehler Publishers, San Francisco, Canada.

UITP. 2001. Better Mobility in Urban Areas.

UITP. 2005. International Association of Public Transport, A UITP position paper. Available from Internet: <http:// www.uitp.com>.

United Nations Secretary-General: Guidelines on cooperation between the United Nations and the Business Community, A/AC. 253/21. 2000. Available from Internet: <www. un.org/partners/business/guide.html>.

Vinck, S. 2000. Quality and customer satisfaction in public transport, in $52^{\text {nd }}$ International Congress Stuttgart"2000. Available from Internet: <www.art.man.ac./transres/lect6. htm>. 